Comparison of oral, enteral and parenteral feeding in HIV

\begin{tabular}{|c|c|c|c|c|}
\hline & Advice only & Oral supplements & Enteral nutrition & Parenteral nutrition \\
\hline $\begin{array}{l}\text { No } \\
\text { No with AIDS (\%) } \\
\text { Mean CD4 count } \\
\left.\text { Range (cells/mm } \text { m }^{3}\right) \\
\text { Mean BMI } \\
\text { (range) } \\
\text { Mean weight (kg) } \\
\text { (range) } \\
\text { Mean wt loss (kg) } \\
\text { (range) } \\
\text { (mean \% wt loss) } \\
\text { Mean wt change (kg) } \\
\text { over three months (range) }\end{array}$ & $\begin{array}{l}14 \\
3(27 \%) \\
177 \\
(10-560) \\
22 \cdot 6 \ddagger \\
(20-25) \\
64 \cdot 1 \\
(41 \cdot 3-92 \cdot 1) \\
1 \cdot 0 \\
(0-9 \cdot 0) \\
(1 \cdot 5 \%) \\
-0 \cdot 6 \\
(-7 \cdot 0 \text { to }+9 \cdot 0)\end{array}$ & $\begin{array}{l}24 \\
7(29 \%) \\
130 \\
(10-520) \\
20 \cdot 2 \\
(17-23) \\
62 \cdot 9 \\
(45-76) \\
9 \cdot 5 \S \\
(0-36) \\
(13 \%) \\
0 \cdot 36 \\
(-11 \cdot 0 \text { to }+14 \cdot 5)\end{array}$ & $\begin{array}{l}10 \\
9 \star \\
14 \dagger \\
(0-30) \\
20 \cdot 2 \\
(19-23) \\
60 \cdot 5 \\
(49 \cdot 4-70 \cdot 8) \\
18 \| \\
(5-38) \\
(13 \%) \\
3 \cdot 01 \\
(-4 \cdot 1 \text { to }+8 \cdot 8)\end{array}$ & $\begin{array}{l}3 \\
3(100 \%) \\
10 \\
(0-20) \\
- \\
50 \cdot 5 \\
(47 \cdot 5-52) \\
22 \cdot 2 \\
(16 \cdot 5-28) \\
(31 \%) \\
-\end{array}$ \\
\hline
\end{tabular}

dietary records. Dietary interventions were based on the assessment of the dietician and the preferences of the patients involved. Proportions of patients with the acquired immune deficiency syndrome (AIDS) were compared by chi square analysis. CD4 counts, basal metabolic index (BMI) and weights of patients in each group were compared by unpaired $t$ test analysis.

Fifty one patients were seen by the designated dietician during the period of the study. Of these $48(94 \%)$ were male and their mean age was 38.5 years (range $18-57$ years). Forty two patients $(82 \%)$ were Caucasian and nine (18\%) were of Asian origin. Thirty four patients $(67 \%)$ had a diagnosis of AIDS.

Fourteen patients $(27 \%)$ received dietary advice only. This group had a mean CD4 + cell count of $177 / \mathrm{mm}^{3}$; mean BMI was 22.6 and mean weight loss prior to dietary consultation was only $1 \mathrm{~kg}$. The mean weight change over the three month period following dietary advice was a reduction of $0.6 \mathrm{~kg}$. Twenty four patients $(47 \%)$ were given oral nutritional supplements. This group of patients had more advanced disease with a mean $\mathrm{CD} 4+$ cell count of $130 / \mathrm{mm}^{3}$; mean BMI was 20.2 and mean weight loss prior to dietary consultation was $9.5 \mathrm{~kg}$. Oral supplementation was associated with a mean weight gain of $0.36 \mathrm{~kg}$ over three months. Ten patients $(20 \%)$ received enteral nutrition which was administered via a percutaneous endoscopic gastrostomy (PEG) tube in two cases. The mean CD4 + cell count of patients receiving enteral nutrition was only $14 / \mathrm{mm}^{3}$ and $90 \%$ had a diagnosis of AIDS. Mean BMI was 20.2 and mean weight loss prior to dietary consultation was $18 \mathrm{~kg}$ representing a $23 \%$ reduction of baseline weight. Enteral feeding was associated with a weight gain of over $3 \mathrm{~kg}$ over three months. Three patients received parenteral feeding, all with a diagnosis of AIDS complicated by enteropathy and opportunistic infections. Long-term nutrition was self-administered via a Hickman line (data summarised in the table).

The patients in this study had relatively advanced disease and the intensity of dietary intervention showed a significant correlation with the stage of disease and previous weight loss. However, the results show that nutritional support, particularly enteral feeding, was frequently delayed until very substantial weight loss had occurred. More aggressive dietary intervention should therefore be considered, particularly in patients with advanced disease and multiple concurrent problems.

Dietary advice and oral nutritional supplementation are useful in the early stages of infection and may help to maintain baseline weight. ${ }^{4}$ Our results showed that oral supplementation and enteral nutrition were both associated with a mean weight gain over three months. Enteral feeding produces an increase in body cell mass ${ }^{5}$ and the magnitude of the response to enteral feeding in our patients was similar to that reported previously. Parenteral nutrition can be effective but is very expensive and should be reserved for selected patients who are unable to tolerate enteral feeding. H HEWIS Fosse Health Trust Gipsy Lane, Humberstone, Leicester LE5 OTD, UK A J PALFREEMAN
Department of Genitourinary Medicine Leicester Royal Infirmary NHS Trust, Infirmary Square, Leicester LE1 5WW, UK Mepartment of Infectious Diseases and Tropical Medicine, Leicester Royal Infirmary NHS Trust, Infirmary Square,
Leicester LE1 SWW, UK

Address correspondence to Dr M J Wiselka.

1 Chlebowski RT, Grosvenor MB, Bernhard NH, Morales LS, Bulcavage LM. Nutritional status, gastrointestinal dysfunction, and survival in patients with AIDS. $\mathrm{Am} \mathscr{f}$ Gastroenterol 1989;84:1288-93.

2 Kotler DP, Tierney A, Wang J, et al. The magnitude of body cell mass depletion in the timing of death from wasting in AIDS. Am $\mathcal{F}$ Clin Nutr 1989a;50:444-9.

3 Timbo BB, Tollefson L. Nutrition: A cofactor in HIV disease. 7 Am Diet Assoc 1994;94:1019-22.

4 Hyman C, Kaufman S. Nutritional impact of acquired immune deficiency syndrome: a unique counselling opportunity. $₹$ Am Diet Assoc 1989;89:520-7.

5 Kotler DP, Tierney A, Ferraro R et al. Enteral alimentation and repletion of body cell mass in malnourished patients with acquired immunodeficiency syndrome. $A m \mathcal{F}$ Clin Nutr 1991;53:149-54.

\section{The "Kumasi modified" two glass urine test and urinary schistosomiasis}

The aetiology of non gonococcal urethritis is myriad $^{1}$ and with the exception of chlamydia infection, investigations are often unrewarding. In the assessment of a patient with suspected urethritis but no overt discharge, the two glass urine test $^{2}$ is often carried out. We have modified this test by centrifuging urine 
from both glasses after the original test has been carried out and looking at the wet preparation of the deposits under the $\times 40$ objective lens of a microscope. This has been helpful in elucidating patients with asymptomatic urinary schistosomiasis.

Over a four year period (1991-94), we undertook 840 such "modified" two glass urine tests. Of this, $52(6 \%)$ showed Schistosoma haematobium, the treatment of which led to a resolution of the urethritis. The patients involved, who were adults, did not have a history of terminal haematuria which would have alerted a clinician to the probable diagnosis of urinary schistosomiasis. A history of contact with water and past haematuria which abated spontaneously or after local herbal preparations were taken, was elicited on re-questioning. Two-thirds of these patients resided in a known schistosomiasis endemic area of the country. We would have missed this diagnosis if the modified test had not been carried out.

It is suggested that in patients hailing from schistosomiasis endemic areas reporting with a suspected urethritis for which no cause has been found, the "Kumasi modified" two glass test could be useful in elucidating the presence or otherwise of $S$ haematobium, whose treatment will prevent the development of complicated schistosomiasis.

YAW ADU-SARKODIE Komfo Anokye Teaching Hospital PO Box 1934 Kumasi

1 Mitchell SA, Shukla SR, Thin RN. Aetiology of non gonococcal urethritis: a possible relation to other infections. Int $f$ STD AIDS 1990;1:429-31.

2 Anonymous. Urethral discharge: diagnostic. In: Adler M W ed. $A B C$ of Sexually Transmitted diseases. 2nd ed. London BMA. 1990.

Accepted for publication 9 July 1996.

\section{Reasons for condom failure among chlamydia infected patients attending a department of genitourinary medicine in Copenhagen}

Safer sex with consistent and correct use of condoms in the case of sexual intercourse outside of longstanding, mutually monogamous relationships has been, and still is, the main message of public educational campaigns for the prevention of HIV infection in Denmark. In recent years several reports have indicated an increased use of condoms. ${ }^{1-3}$ However, as many as $40 \%$ of young adolescents do not use barrier contraception at first sexual intercourse, ${ }^{1}$ and a recent study showed that $38 \%$ of women attending a genitourinary medicine (GUM) clinic in London never or only occasionally used condoms. ${ }^{4}$ When engaged in vaginal intercourse with non-regular partners only $44 \%$ always used condoms. ${ }^{4}$

If we want to optimise our public campaigns recommending the use of condoms in case of casual sexual intercourse, it is necessary to expose in depth the reasons for inconsistent or incorrect use of condoms. In order to evaluate this aspect we asked 49 consecu- tive chlamydia positive heterosexual patients attending the department of GUM at Bispebjerg Hospital to complete an anonymous standardised questionnaire. One woman did not answer the questionnaire and was therefore excluded from analysis, giving a completion rate of $98 \%$. Of the 48 included patients, 24 were males and 24 were females. Each patient was asked to specify which of the statements in 20 questions fits with their attitude to or experience with condoms. At least one and maximally three of the items given in the table could be ticked off as correct by the patient.

\section{Barriers to use}

Decreased pleasure of sex, irritation due to interruption of the sexual act or unromantic feelings played a role for 24 patients $(50 \%)$ who chose not to use condoms. These emotional reasons were found with the same prevalence among males and females (table). Only two male patients had significant erection problems when using condoms.

\section{Sex with regular partner}

Sexual relationship with a steady partner was a major reason for having unsafe sex in 5 patients $(10 \%)$. Especially female patients relied on this information as a valid indicator for choosing not to use condoms (table). A male patient reported that he knew his sexual partners sufficiently well as the reason for having sex without a condom.

\section{Alcohol intake}

A total of 12 patients (25\%) mentioned that alcohol with sex were an essential factor for not using condoms. There seems to be no major difference between males and females in their attitude to drinking alcohol in relation to sexual intercourse (table).

\section{Self-efficacy}

Low self-esteem was a contributing factor in 11 patients (23\%), all being females. They found that items $1-5$ in the table had major impact on their decision of not using condoms.

\section{Condom not available}

Eight patients (17\%) stated that lack of a condom in the actual risk situation was the reason for having practised unsafe sex.

\section{Using other methods of contraception}

Seven patients (15\%) had not used condoms as other forms of contraceptive methods were in practise simultaneously (table).

\section{Intellectual insufficiency}

Not using a condom (although available), lack of care or considering not being in risk of contracting a sexually transmitted disease were primarily mentioned by male patients. Nine of eleven patients that responded positively to statements $6-8$ in the table were males. In addition stupidity and slovenliness were noticed by a female and a male patient, respectively. 